INSTITUT NATIONAL DE LA STATISTIQUE ET DES ETUDES ECONOMIQUES

Série des Documents de Travail du CREST

(Centre de Recherche en Economie et Statistique)

\author{
$\mathrm{n}^{\circ}$ 2011-02 \\ The Possible Shapes of Recoveries \\ in Markov-Switching Models \\ F. BEC ${ }^{1}$ \\ O. BOUABDALLAH ${ }^{2}$ \\ L. FERRARA ${ }^{3}$
}

Les documents de travail ne reflètent pas la position de l'INSEE et n'engagent que leurs auteurs.

Working papers do not reflect the position of INSEE but only the views of the authors.

1 THEMA, Université de Cergy-Pontoise and CREST. Email : bec@ensae.fr

2 Banque de France, DGEI-DCPM.

3 Banque de France, DGEI-DCPM. 


\title{
The possible shapes of recoveries in Markov-Switching models
}

\author{
FRÉDÉRIQUE BEC ${ }^{1}$ \\ OTHMAN BOUABDALlaH ${ }^{2}$ \\ LAURENT FERRARA ${ }^{3}$
}

January 18, 2011

\begin{abstract}
This paper explores the various shapes the recoveries may exhibit within a MarkovSwitching model. It relies on the bounce-back effects first analyzed by Kim, Morley and Piger (2005) and extends the methodology by proposing i) a more flexible bounce-back model, ii) explicit tests to select the appropriate bounce-back function, if any, and iii) a suitable measure of the permanent impact of recessions. This approach is then applied to post-WWII quarterly growth rates of US, UK and French real GDPs.
\end{abstract}

Keywords: Markov-Switching models, bounce-back effects, asymmetric business cycles. JEL classification: E32, C22.

Acknowledgments: We thank Marine Carrasco, Guy Laroque, James Morley and participants at the Econometrics seminar of the GREQAM, Aix-Marseille University, at the Banque de France seminar, Paris, and at the CREST Macroeconomics laboratory seminar, Paris, for helpful discussions. We are also grateful to Marine Carrasco, Jim Hamilton and Frédéric Karamé for providing some codes. Of course, the usual disclaimer applies.

\footnotetext{
${ }^{1}$ THEMA, Université de Cergy-Pontoise and CREST. email: bec@ensae.fr

${ }^{2}$ Banque de France, DGEI-DCPM.

${ }^{3}$ Banque de France, DGEI-DERIE.
} 


\section{Introduction}

Since the renewal of nonlinear econometrics theory two decades ago, the asymmetric dynamics of real output growth over the business cycle has been widely acknowledged by empirical studies — see the early contributions by e.g. Neftci [1984], Hamilton [1989], Luukkonen and Terasvirta [1991] or Beaudry and Koop [1993]. So far, the MarkovSwitching (MS) model developed by Hamilton [1989] is the most popular framework for the business cycle empirical analysis. Actually, this model and its direct extensions by e.g. Sichel [1994], Clements and Krolzig [1998] or Clements and Krolzig [2003] have proved to be quite successful in disentangling expansion vs recession periods.

Nevertheless, one implication of Hamilton's model is quite pessimistic in that it predicts that the effects of a recession will be permanent for the output level. In other words, this model implies that following the end of a recession, the economy will grow from a permanently lower level. From an economic theory perspective, the conclusions of endogenous growth models regarding the long term impact of recessions are not clearcut. Some authors as e.g. Caballero and Hammour [1994] or Aghion and Saint Paul [1998] conclude that the cleansing effect of recessions has a permanent positive impact on output. By contrast, a negative long term impact of recessions is predicted by Martin and Rogers [1997]'s model, due to the adverse effect of recessions on learning-by-doing and hence on human capital accumulation. A negative long term effect is also predicted by Stadler [1990] when technology is endogenous or by Stiglitz [1993] and Aghion, Askenazy, Berman, Cette and Eymard [2008] in presence of credit markets imperfections. Recent empirical studies tend to support the latter view. For instance, using the large panels of countries from the World Bank and Penn World Tables, Cerra and Saxena [2005] point to a cumulative output loss in recession which averages $7.5 \%$. This figure falls to 3-4\% when only high-income countries are considered. Furceri and Mourougane [2009]'s analysis of 30 OECD countries focuses on financial crises only, and exhibits a permanent loss in the output level of $4 \%$ on average.

These recent results contrast with Friedman [1993]'s view, first advocated by the 
author in $1964^{4}$, according to which "a large contraction in output tends to be followed on by a large business expansion; a mild contraction, by a mild expansion". Indeed, such a view allows for revivals as strong as the previous recession and hence possibly contradicts Hamilton's model prediction regarding long term effects. This possibility was first explored by Sichel [1994] who allowed for a third regime in its MS model. From his empirical findings, this author argued that postwar US business cycles typically consist of three phases: contraction, followed by high-growth recovery and then a period of moderate growth. Nevertheless, Sichel's model does not allow the recovery to depend on the duration of the previous recession. This next step is done by Kim, Morley and Piger [2005]: While maintaining the two-regime assumption of Hamilton's model, these authors have extended it so as to allow for more flexible end of recessions than the "L"-shaped recessions implied by Hamilton's model. In particular, they introduce a bounce-back term - or function - in the expression of the state-dependent mean which accounts for the possibility of a post-recession recovery: following the end of a recession, the output growth rate could be large enough to imply a recovery towards the output level before the recession. This extended framework allows not only for "U"-shaped or "V"-shaped recessions, but also for recoveries which explicitly depend on the duration and depth of the previous recession. Estimating this model from US real GDP postwar quarterly data, Kim et al. [2005] find a permanent loss in the output level by $0.4 \%$, which is roughly 10 times smaller than the one found from Hamilton's model.

Our main contribution to this empirical literature is to propose a more general version of the bounce-back (BB) MS model which extends the existing one in two directions. Firstly, contrary to the models considered in Kim et al. [2005] or Morley and Piger [2009], it allows the bounce-back effect to appear later than immediately after the trough. This extension seems relevant for countries which are less flexible than, say, the U.S. For instance, some countries may experience more inertia around a trough in terms of GDP growth rate dynamics which in turn may delay the bounce-back effect. Secondly, our

\footnotetext{
${ }^{4}$ See "Monetary Studies of the National Bureau", The National Bureau Enters Its 45th Year, 44th Annual report, 1964, pp. 7-25.
} 
general bounce-back MS model makes it possible to let the data select the appropriate bounce-back shape. Actually, it allows for a larger set of recovery shapes than the existing ones and also encompasses the latter: the "depth"-based bounce-back MS model (denoted BBD hereafter), the "U"-shaped, the "V"-shaped recovery bounce-back MS models (denoted BBU and BBV) as well as Hamilton's original model (denoted H) are special cases of ours. As such, they can be tested from simple linear restrictions on the coefficients of the bounce-back function. Since in our general framework Hamilton [1989]'s measure of the permanent effect of recessions has no closed-form solution, we also propose a measure adapted to the general case.

Finally, our work proposes an international comparison of these bounce-back effects using post World War II quarterly growth rates of US, UK and French real GDPs. The empirical results emphasize the relevance of the extended framework and the countryspecific nature of the shape of recoveries. They also reveal an important contribution of the bounce-back effect in reducing the long term negative impact of recessions on the output level.

The paper is organized as follows. Section 1 presents and discusses the bounceback extensions of Hamilton's model. Section 2 describes the data and the linearity test which is the preliminary step of the empirical analysis. Section 3 presents the MS models estimates and the specification tests. In Section 4, we examine the implications of our results for the shape of the recovery as well as the permanent impact of recessions on the output level in each country. Section 5 concludes.

\section{Bounceback effects}

\subsection{The basic Hamilton MS-model}

Let $y_{t}$ denote the log of real output. The model we will consider throughout this paper is the following:

$$
\phi(L)\left(\Delta y_{t}-\mu_{t}\right)=\varepsilon_{t},
$$


where $\Delta$ is the first difference operator, $\phi(L)$ is a lag polynomial of order $p$ with roots lying outside the unit circle, $\varepsilon_{t}$ i.i.d. $\mathcal{N}(0, \sigma)$ and $\mu_{t}$ is allowed to switch across regimes. The Markov-Switching model proposed by Hamilton [1989] postulates the existence of an unobserved variable, denoted $S_{t}$, which takes on the value zero or one. $S_{t}$ characterizes the "state" or "regime" of the economy at date $t$. The standard version of Hamilton's model could be written as:

$$
\mu_{t}=\gamma_{0}+\gamma_{1} S_{t}
$$

which means that the growth rate of $y_{t}$ is $\gamma_{0}$ if $S_{t}=0$ and $\gamma_{0}+\gamma_{1}$ otherwise. Here, $S_{t}=1$ is identified as the recession regime by assuming $\gamma_{0}>0$ and $\gamma_{0}+\gamma_{1}<0$. Hamilton [1989] further assumes that the unobserved state variable $S_{t}$ is the realization of a two-state Markov chain with transition probability $P\left(S_{t}=j \mid S_{t-1}=i\right)=p_{i j}$. This Markov chain implies that $S_{t}$ depends on past realizations of $y$ and $S$ only through $S_{t-1}$. The model given by equations (1) and (2) allows for an asymmetric behavior across regimes. For instance, the expansion regime may be characterized by long and gradual upward moves if $\gamma_{0}$ is positive and small and $p_{00}$ is close to one, while the recession regime may correspond to sharp and short declines if $\gamma_{1}$ is negative and large in absolute value and $p_{11}$ is small. It is worth noticing that the current change in output can be independent of the state that prevailed last period, as in a random walk, if $p_{00}=1-p_{11}$.

\subsection{Existing bounce-back functions}

Recently, Kim et al. [2005] have proposed extensions of equation (2) in the Hamilton's model presented above which allow for the length and/or depth of each recession to influence the growth rate of output in the periods immediately following the recession. We will follow their terminology and refer to these models as "bounce-back" MS models. They consider three kinds of bounce-back functions, which correspond respectively to "U" - or "V" - shaped recessions, or "Depth" nonlinear bounce-back models. For these models, equation (1) above remains unchanged since the bounce-back function is introduced in the regime-dependent mean of $\Delta y_{t}$. In the $\mathrm{U}$-shaped recession model, denoted 
BBU hereafter, the equation for $\mu_{t}$ becomes:

$$
\mu_{t}=\gamma_{0}+\gamma_{1} S_{t}+\lambda \sum_{j=1}^{m} \gamma_{1} S_{t-j}
$$

where the $m$ and $\lambda$ parameters govern respectively the duration and the magnitude of the bounce-back effect. For the V-shaped recession model, denoted BBV, the bounce-back function takes the form:

$$
\mu_{t}=\gamma_{0}+\gamma_{1} S_{t}+\left(1-S_{t}\right) \lambda \sum_{j=1}^{m} \gamma_{1} S_{t-j} .
$$

Finally, the expression of $\mu_{t}$ in the "Depth" bounce-back model, denoted BBD, is:

$$
\mu_{t}=\gamma_{0}+\gamma_{1} S_{t}+\lambda \sum_{j=1}^{m}\left(\gamma_{1}+\Delta y_{t-j}\right) S_{t-j}
$$

The value of the bounce-back parameter, $\lambda$, is crucial for the shape of the recovery. First, it is worth noticing that all these models differ from Hamilton's model if and only if $\lambda \neq 0$. Then, for a bounce-back effect to occur, this parameter must be negative: in this case, the last term of the right hand side of the three equations above is positive and makes the growth rate larger for the quarters immediately following a recession. To illustrate the difference between these bounce-back models and Hamilton's original model, we simulate the following process:

$$
y_{t}=y_{t-1}+\mu_{t}
$$

where $\mu_{t}$ is given in equations (2), (3), (4) and (5) respectively, with $\gamma_{0}=1, \gamma_{1}=-2$, $m=4$ and $\lambda=\{-0.2,-0.4\}$. The initial value of $y_{t}$ is set to 10 . At time $t=6$, the state variable switches from the expansion to the recession regime, and remains in the latter for three consecutive quarters before switching back to the expansion regime. Figure 1 reports the impact of these various bounce-back functions on the growth rate of $y_{t}$ for $\lambda=-0.2$ (top panel) and $\lambda=-0.4$ (bottom panel). First, by contrast with Hamilton's model — denoted $(\mathrm{H})$ in this Figure, all bounce-back models imply growth rates values greater than $\gamma_{0}$ for the four quarters following the end of the recession. Of 
course, this effect would last longer for larger values of $m$. It can be seen that the value of $\lambda$ basically influences the magnitude of the recovery: when $\lambda=-0.2$, the larger growth rate of the bounce-back models reaches almost $2.5 \%$ at time $t=9$. When $\lambda=-0.4$, the maximum growth rate reaches around $3.5 \%$ at the same time. Then, the main difference between the bounce-back functions comes from the BBV function which, due to the presence of $\left(1-S_{t}\right)$, becomes active only when the recession is over and $S_{t}$ comes back to zero. Finally, for the set of parameters values retained in this experiment, the BBD function is the one which generates the largest growth rates just one quarter after the beginning of a recession: the bounce-back effect of this function is further enhanced by the negative values of the recent past of $\Delta y$. The accumulation of these $\mu_{t}$ 's starting from $y_{0}=10$, gives the impact of these various bounce-back functions on $y_{t}$ in levels. The resulting $y_{t}$ 's, together with a linear trend with slope $\gamma_{0}$, are plotted in Figure 2, again for $\lambda=-0.2$ and -0.4 . The solid line, which represents the $y_{t}$ series resulting from Hamilton's model, shows the permanent effect of recession this model implies: from the trough on, $y_{t}$ increases at the expansion growth rate $\gamma_{0}$ only, i.e. it grows from a permanently lower level. By contrast, depending on the value of $\lambda$, the bounce-back models may predict a partial recovery, as illustrated by the $\mathrm{y}(\mathrm{BBU})$ and $\mathrm{y}(\mathrm{BBV})$ curves in the top panel of Figure 2, a complete recovery (see the $y(B B D)$ curve in the same panel) or even a growth of output level from a permanently higher level, as shown in the bottom panel of Figure 2 which corresponds to a large $\lambda$ in absolute value. Such a case is actually predicted by endogenous growth theories which belong to the Schumpeterian tradition (see e.g. Caballero and Hammour [1994] or Aghion and Saint Paul [1998]). These simulated paths emphasize the flexibility of bounce-back models compared to Hamilton's original model. Finally, the U- and V-shapes of the corresponding bounceback functions are well illustrated by Figure 2: the y(BBU) curves are softer during and after recessions than the $\mathrm{y}(\mathrm{BBV})$ curves. 

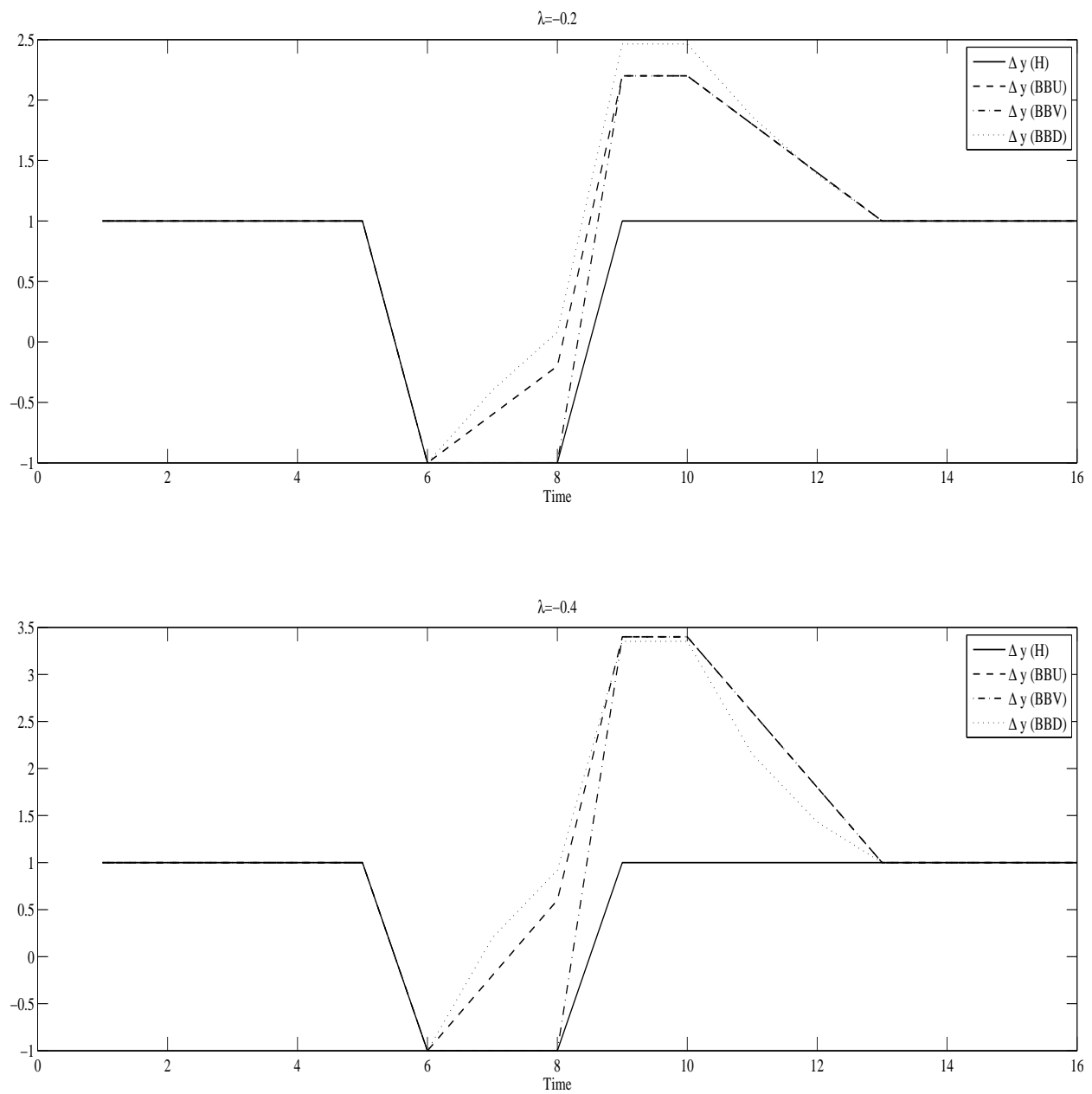

Figure 1: Impact of bounce-back effects on growth rates 

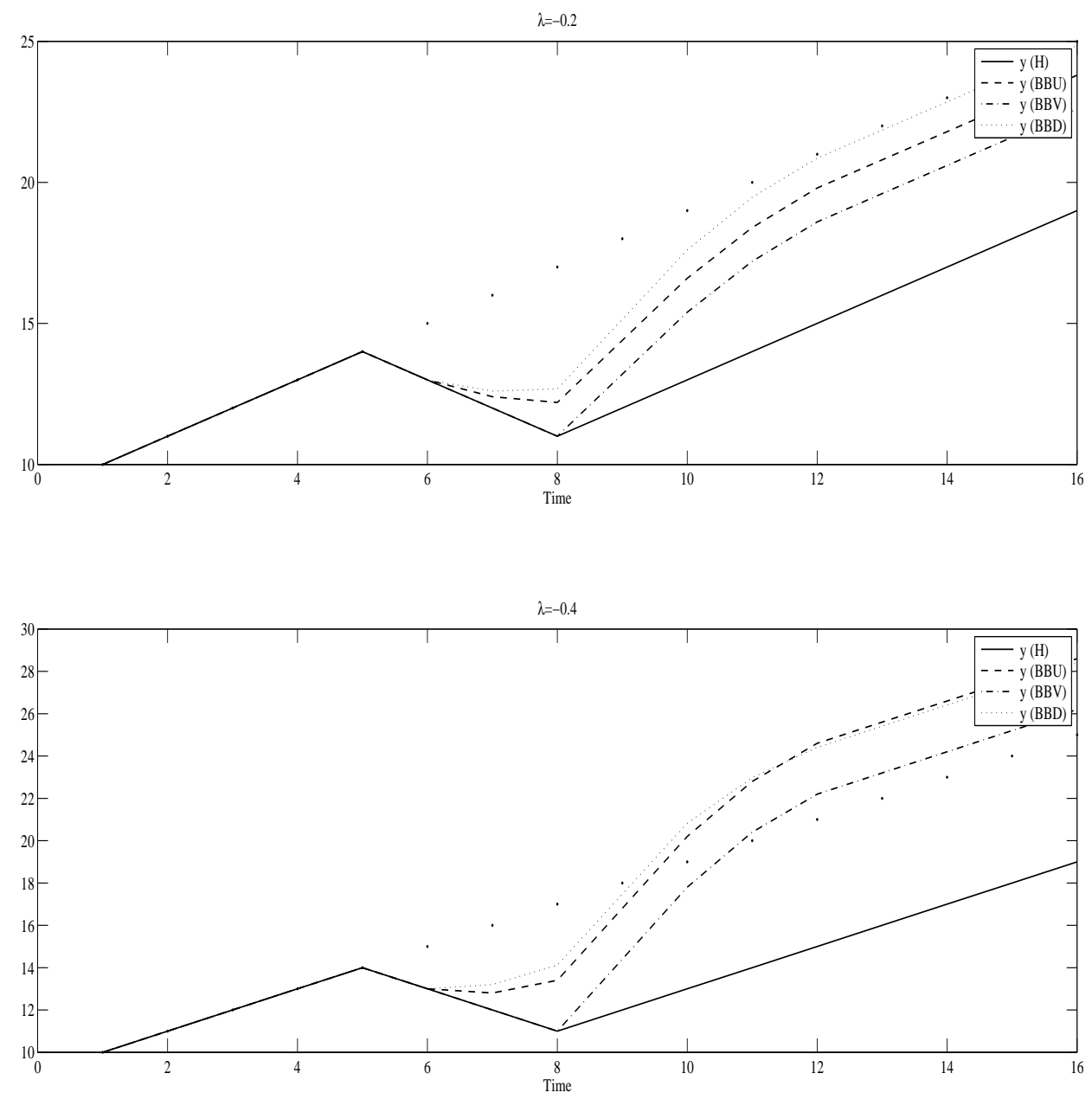

Figure 2: Impact of bounce-back effects on levels 


\subsection{Our proposed bounce-back framing}

As stressed in the introduction, we wish to allow for a bounce-back effect which happens not necessarily immediately after the trough date, but which may possibly be delayed by a few quarters instead. To this end, we introduce a new parameter, $\ell \geq 0$, which denotes the delay, in terms of quarters after the trough, before the bounce-back effect begins. This bounce-back framing MS model, denoted $\operatorname{BBF}(p, m, \ell)$ hereafter, is given by equation (1) with:

$$
\mu_{t}=\gamma_{0}+\gamma_{1} S_{t}+\lambda_{1} S_{t} \sum_{j=\ell+1}^{\ell+m} \gamma_{1} S_{t-j}+\lambda_{2}\left(1-S_{t}\right) \sum_{j=\ell+1}^{\ell+m} \gamma_{1} S_{t-j}+\lambda_{3} \sum_{j=\ell+1}^{\ell+m} \Delta y_{t-j} S_{t-j}
$$

In order to illustrate the bounce-back effect possibly generated by this model, we have done the same simulation as the one reported in Figure 1, retaining the same parameters values for $\gamma_{0}$ and $\gamma_{1}$ and considering a 3 -quarter recession starting at $t=$ 6. Here, we arbitrarily set $\lambda_{1}=-0.1, \lambda_{2}=-0.2$ and $\lambda_{3}=-0.3$. Figure 3 below reports the corresponding impact on the growth rate for $\ell \in\{0,1,2\}$. The case where $\ell=0$ corresponds roughly to an intermediate case between the BBU and BBD models presented in the previous section. The most interesting case is the one where $\ell=1$, i.e. an intermediary case lasting shorter than the recession itself: in this configuration,

the bounce-back effect is not activated at the beginning of the recession, but is instead lagged by $\ell$ quarters. Finally, the case where $\ell=2$, so that $\ell+1$ is exactly the length of the recession considered in this example, looks like the BBV model at date $t=6$, but then the bounce-back effect lasts two quarters longer than in the simple BBV case.

\subsection{A formal test of recoveries shapes}

It is worth noticing that model (6) above encompasses the BB models presented in Kim et al. [2005]. As discussed in the previous section, the different MS models considered above imply different output behavior during and after a recession. Therefore, the choice of the bounce-back function is crucial for forecasting purpose. Morley and Piger [2009] propose to select the model following various information criteria. We actually believe 


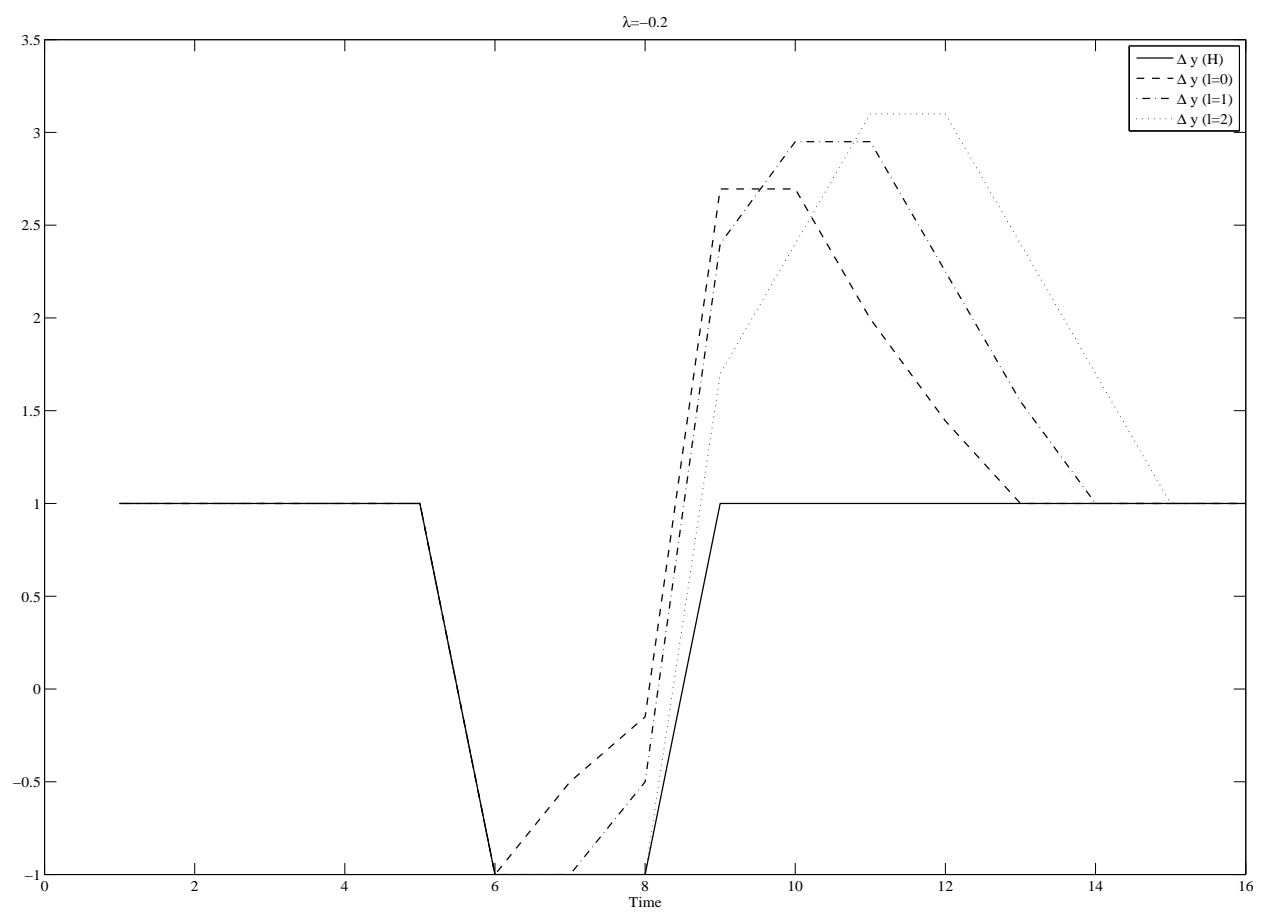

Figure 3: Impact of $\operatorname{BBF}(0,4, \ell)$ 's model on growth rates 
that these criteria prove very useful for model's comparison when formal testing is not possible, i.e. for non-nested models. Nevertheless, it is well-known that these information criteria do not perform very well in small sample analysis or in presence of nonlinear parameters. For this reason, we will use the BBF model from which Hamilton's, BBU, $\mathrm{BBV}$ and $\mathrm{BBD}$ models can be retrieved by imposing linear restrictions on its parameters values. Hamilton's original model corresponds, in equation (6), to the null hypothesis:

$$
H_{0}^{H}: \lambda_{1}=\lambda_{2}=\lambda_{3}=0
$$

Then, the $\operatorname{BBU}(p, m, \ell)$ is a constrained version of the $\operatorname{BBF}(p, m, \ell)$ in which the following linear restrictions on the parameters hold:

$$
H_{0}^{U}: \lambda_{1}=\lambda_{2}=\lambda \text { and } \lambda_{3}=0
$$

with $\lambda$ a strictly negative real parameter. Similarly, the $\operatorname{BBV}(p, m, \ell)$ model is obtained from equation (6) by imposing the following null hypothesis:

$$
H_{0}^{V}: \lambda_{1}=\lambda_{3}=0
$$

Finally, the general model given in (6) reduces to a $\operatorname{BBD}(p, m, \ell)$ model under the joint restrictions:

$$
H_{0}^{D}: \lambda_{1}=\lambda_{2}=\lambda_{3}=\lambda
$$

Remark that the models considered by Kim et al. [2005] and given by equations (3), (4) and (5) correspond respectively to the $\operatorname{BBU}(p, m, \ell), \operatorname{BBV}(p, m, \ell)$ and $\operatorname{BBD}(p, m, \ell)$ models in the particular case where $\ell=0$. It is worth noticing that all the null hypotheses $H_{0}^{U}, H_{0}^{V}$ and $H_{0}^{D}$ above are nuisance-parameter free. Hence, they can be tested using a standard Likelihood Ratio - or Lagrange Multiplier, or Wald — test statistics which in turn is asymptotically Chi-squared distributed with two degrees of freedom for $H_{0}^{U}, H_{0}^{V}$ and $H_{0}^{D}$. Finally, assuming $m$ and $\ell$ are known, the LR test statistics of the null hypothesis $H_{0}^{H}$ against the $\operatorname{BBF}(p, m, \ell)$ alternative is asymptotically Chi-squared distributed with three degrees of freedom. 


\section{The data}

The quarterly real GDP data used for the United Kingdom come from the Office of National Statistics and are available for the period 1955Q1-2010Q1. For France, we use data from the INSEE which are available from 1949Q1 to 2010Q1. U.S. data come from the Bureau of Economic Analysis and the sample starts in 1947Q1.

Before turning to the BBF model estimation, let us first discuss the business cycles dating for these samples since it will provide a benchmark to evaluate the relevance of the regime-switching model's estimates. We will also perform the linearity test proposed by Carrasco, Hu and Ploberger [2009].

\subsection{Business Cycles dates}

Following the "classical" business cycle approach as described by Burns and Mitchell [1947], the NBER's Business Cycle Dating Committee provides the U.S. business cycle turning points: these dates will be used in the analysis below. Outside the U.S., "classical" business cycle dating studies include Birchenhall, Osborn and Sensier [2001] or Harding and Pagan [2002]. Both studies rely on the Bry and Boschan [1971] algorithm, as adapted to quarterly data. For French and UK business cycle dating, we will follow Birchenhall et al. [2001] approach: a peak is identified at $t$ if the log level of quarterly real GDP $\left(y_{t}\right)$ is strictly greater than the values for the subsequent two quarters (i.e. $y_{t+1}-y_{t}<0$ and $\left.y_{t+2}-y_{t}<0\right)$ while also being at least as large as all values within a year in the past (i.e. $y_{t-i}-y_{t} \leq 0$, for $i=1, \ldots, 4$ ) and in the future (i.e. $y_{t+i}-y_{t} \leq 0$, for $i=1, \ldots, 4)$. The resulting peak and trough dates for UK and French real GDPs as well as the US business cycle NBER dating ${ }^{5}$ are reported in Table 1. This Table clearly points to the fact that the US have experienced more business cycles than the UK and France: over the common sample 1955-2010, there were nine recessions in the US, compared to five and four in the UK and France respectively. One explanation is

\footnotetext{
${ }^{5}$ Note that the NBER method is quite different from our approach in that it uses a set of monthly data. Nevertheless, Morley, Piger and Tien [2009] show that the recession dates obtained from both approaches yield quite similar results.
} 
Table 1: Business cycle turning points

\begin{tabular}{cccccc}
\hline \hline \multicolumn{2}{c}{ US } & \multicolumn{2}{c}{ UK } \\
\hline Peak (a) & Trough (b) & Peak (a) & Trough (b) & Peak (a) & Trough (b) \\
\hline 1948Q4 (12) & 1949Q4 (4) & & & & \\
1953Q2 (14) & 1954Q2 (4) & & & & \\
1957Q3 (13) & 1958Q2 (3) & & & & \\
1960Q2 (8) & 1961Q1 (3) & & & & \\
1969Q4 (35) & 1970Q4 (4) & & & & \\
1973Q4 (12) & 1975Q1 (5) & 1973Q2 (-) & 1975Q3* (9) & 1974Q3 (-) & 1975Q2 (3) \\
1980Q1 (20) & 1980Q3 (2) & 1979Q2 (15) & 1981Q1 (7) & 1980Q1 (19) & 1980Q4 (3) \\
1981Q3 (4) & 1982Q4 (5) & & & & \\
1990Q3 (31) & 1991Q1 (2) & 1990Q2 (37) & 1992Q2 (8) & 1992Q3 (47) & 1993Q2 (3) \\
2001Q1 (40) & 2001Q4 (3) & & & & \\
2007Q4 (24) & 2009Q2 (6) & 2008Q1 (63) & 2009Q3 (6) & 2008Q1 (59) & 2009Q3 (6) \\
\hline \hline
\end{tabular}

(a): expansion duration in quarters, from previous trough to this peak.

(b): contraction duration in quarters, from peak to trough.

Dates in italic require future confirmation. ${ }^{*}$ See text.

that after the end of World War II, the United Kingdom and France experienced almost three decades of sustained growth. As a result, only one recession occurred in the UK before the seventies, while none was observed in France. Regarding the latter, it is worth mentioning that this GDP series has been corrected for the May 1968 outlier due to a national strike. For the UK data, we have followed Birchenhall et al. [2001] in rejecting a trough at 1974Q1 while maintaining the one in 1975Q3. These authors choose to reject the first trough because the low value of GDP in that quarter and the subsequent increases in 1974Q2 and 1974Q3 reflect the impact of a three-day week associated with a miners' strike. In all these countries, the duration of expansions is remarkably longer than the one of recessions.

Before turning to the MS models estimation, we first perform the linearity test recently developed by Carrasco et al. [2009] which is specifically suitable against MS alternatives. 


\section{$2.2 \quad$ Linearity test}

Recently, Carrasco et al. [2009] have proposed a class of optimal tests for the constancy of parameters in random coefficients models. Their testing procedure covers the class of Hamilton models, where the parameters vary according to an unobservable Markov chain. An important advantage of their SupTS test is that it only requires estimating the model under the null hypothesis where the parameters are constant. Using the Gauss codes kindly provided by the authors, empirical critical values are computed from 10,000 iterations for a sample size equal to the size of the original data set. The values of the parameters used to simulate the series are those obtained from the estimation of the model under the linear null. The $1 \%, 5 \%$ and $10 \%$ critical values are reported in the last three columns of Table 2. As can be seen in this table, the null hypothesis of parameters stability is strongly rejected against a Markov-switching alternative.

Table 2: Carrasco, Hu and Ploberger linearity test

\begin{tabular}{lccccc}
\hline \hline Series & T & SupTS & $1 \%$ c.v. & $5 \%$ c.v. & $10 \%$ c.v. \\
US & 252 & 11.96 & 4.75 & 3.51 & 2.96 \\
UK & 220 & 15.99 & 4.46 & 3.53 & 3.00 \\
FR & 244 & 12.37 & 4.51 & 3.51 & 3.03 \\
\hline \hline
\end{tabular}

\section{BBF models estimation}

Following Kim et al. [2005], the BBF model given in equation (6) is estimated by maximum likelihood method using the filter presented in Hamilton [1989]. Note that here, due to the terms involving the sum of lagged values of $S_{t}$, one has to keep track of $2^{p+m+\ell+1}$ states versus $2^{p+1}$ when constructing the likelihood function in each period. Standard errors are based on numerical second derivatives. Basically, the autoregressive lag parameter $p$ is chosen as the smallest one which succeeds in eliminating residuals autocorrelation according to the LM test. Computing residuals for MS models is not so 
straightforward. Using the approach described in Kim, Shephard and Chib [1998] and also used in Bec, Rahbek and Shephard [2008], we construct the BBF model residuals from the one-step-ahead prediction distribution functions as follows: From equations (1) and (6), it can be seen that time- $t$ residuals depend on $\xi_{t} \equiv\left(S_{t}, S_{t-1}, \ldots, S_{t-\ell-m-p}\right)$. The one-step-ahead prediction distribution functions are defined by:

$$
\epsilon_{t}=\sum_{i=1}^{2^{p+m+\ell+1}} P\left(\xi_{i t} \mid I_{t-1}\right) \Phi\left(\frac{\hat{\varepsilon}_{i t}}{\hat{\sigma}}\right),
$$

where $\hat{\varepsilon}_{i t}$ denotes the ML estimates of the BBF model residuals in regime $i$ and $\Phi$ is the distribution function of the standard normal. Note that the $P\left(\xi_{i t} \mid I_{t-1}\right)$ 's can be easily obtained as by-products of the filtering algorithm. If the nonlinear model is true and ignoring the effect of estimating parameters, the $\epsilon_{t}$ are approximately standard uniform and iid. We can then map these to our residuals for the BBF model by the standard normal inverse distribution function, $\varepsilon_{t}^{B B F}=\Phi^{-1}\left(\epsilon_{t}\right)$ and then test for the absence of serial correlation. Once the lag length parameter fixed as described above, the choice of $m$ and $\ell$ parameters values is made from a double-grid search for $m=2, \ldots, 6$ and $\ell=0, \ldots, 3$, so as to maximize the likelihood function. In order to identify the regime 1 as a recession regime, we rule out models where $\gamma_{0}+\gamma_{1}>0$ and where $p_{11}<0.5$. The last condition stems from the fact that a recession is formally defined as at least two consecutive quarters of negative growth rate.

The United States Since the estimation of regime-switching models has been shown to be quite sensitive to forgotten structural breaks (see for instance Kim and Nelson [1999]), we follow Morley and Piger [2009] by introducing i) a break in the growth rate mean in the first quarter of 1973 corresponding to the so-called productivity slowdown documented by e.g. Bai, Lumsdaine and Stock [1998] and ii) a break in volatility in the second quarter of 1984 to account for the so-called Great Moderation put forward by McConnell and Perez-Quiros [2000] for instance. Those breaks are introduced as in Kim and Nelson [1999]: For the great moderation, both the conditional variance and the difference in growth rates across regime change, but the change in conditional variance 
is assumed to be proportional to the squared change in the difference in growth rates. For the productivity slowdown, the mean growth rate in the expansion regime is allowed to change.

The log-likelihood, the AIC criterion $^{6}$ and the LR test statistics for the shape of the bounce-back effect are reported in Table 3 below. For the US, the lag order for the bounceback models is set to two: with $p=2$, the LM tests of no serial correlation up to order 4 and 8 are $90 \%$ and $97 \%$ respectively for the bounceback model retained below. With $p=2$, the pair $(m, \ell)=(4,1)$ is found to be the one maximizing the loglikelihood of the BBF model. This means that one quarter after the end of a recession, the bounceback effect is activated for the next four quarters before the GDP growth rate comes back to the expansion regime. In their bounceback models with $\ell$ assumed to be known and fixed to zero, Kim et al. [2005] have found that $p=0$ and $m=6$ following the Schwartz information criterion. From the AIC values reported in the last column of Table 3, it appears that all kinds of MS models considered here (Hamilton original model included) outperform the linear autoregressive models, whatever the number of lags included in the latter up to twelve ${ }^{7}$. It is also worth noticing that according to the AIC, the bounceback models are preferred to Hamilton original model. This is especially true for the BBD which is also the model for which the Likelihood Ratio test p-value, i.e. $79 \%$, is the largest against the $\mathrm{BBF}$ alternative ${ }^{8}$. When looking at the $\operatorname{BBF}(2,4,1)$ estimation results given in Table 4 , one immediately notices that the estimates of $\lambda_{1}, \lambda_{2}$ and $\lambda_{3}$ are quite similar. Hence, the loss of likelihood generated by the constraint that these three coefficients are identical is very close to zero: it falls from -297.70 for the $\operatorname{BBF}(2,4,1)$ model to -297.93 for the $\operatorname{BBD}(2,4,1)$, as can be seen from Table 3 . Actually, the parameters estimates of the BBD model, where $\lambda_{1}=\lambda_{2}=\lambda_{3}$, are quite similar to the ones of the BBF model. According to both models, the average length of a recession,

\footnotetext{
${ }^{6}$ The AIC is defined as in Davidson and MacKinnon [2004], pp. 676-677, so that larger values of the criterion are preferred. The number of parameters retained in the penalty function is denoted $n_{p}$ in the tables.

${ }^{7}$ All results are not reported here but are available upon request from the authors.

${ }^{8}$ The LR statistics is equal to 0.46 and is distributed as a $\chi^{2}(2)$.
} 
Table 3: Comparison of US models

\begin{tabular}{|c|c|c|c|c|c|}
\hline Model & Log-L & $n_{p}$ & $\mathrm{AIC}$ & LR stat & p-val. \\
\hline \multicolumn{6}{|c|}{ Linear } \\
\hline $\operatorname{AR}(1)$ & -310.07 & 5 & -315.07 & & \\
\hline $\operatorname{AR}(2)$ & -307.79 & 6 & -313.79 & & \\
\hline $\operatorname{AR}(3)$ & -305.07 & 7 & -312.07 & & \\
\hline $\operatorname{AR}(4)$ & -304.95 & 8 & -312.95 & & \\
\hline $\operatorname{AR}(8)$ & -304.28 & 12 & -316.28 & & \\
\hline \multicolumn{6}{|c|}{ Bounceback } \\
\hline $\operatorname{BBF}(2,4,1)$ & -297.70 & 12 & -309.70 & & \\
\hline $\operatorname{BBU}(2,4,1)$ & -299.81 & 10 & -309.81 & 4.22 & 0.12 \\
\hline $\operatorname{BBV}(2,4,1)$ & -300.63 & 10 & -310.63 & 5.86 & 0.05 \\
\hline $\operatorname{BBD}(2,4,1)$ & -297.93 & 10 & -307.93 & 0.46 & 0.79 \\
\hline \multicolumn{6}{|c|}{ Hamilton } \\
\hline $\mathrm{H}-\mathrm{AR}(2)$ & -301.90 & 9 & -310.90 & 8.40 & 0.04 \\
\hline \multicolumn{6}{|c|}{ Morley and Piger (2009) } \\
\hline $\operatorname{BBD}(0,6,0)$ & -307.90 & 8 & -315.90 & & \\
\hline
\end{tabular}

Table 4: US Bounce-back models estimates

\begin{tabular}{cccccccccccc}
\hline \hline$\gamma_{0}$ & $\gamma_{1}$ & $\sigma$ & $\lambda_{1}$ & $\lambda_{2}$ & \multicolumn{1}{c}{$\lambda_{3}$} & $\phi_{1}$ & $\phi_{2}$ & $\delta_{\gamma}$ & $\delta_{\gamma, \sigma}$ & $p_{00}$ & $p_{11}$ \\
\hline & & & & \multicolumn{9}{c}{$\operatorname{BBF}(2,4,1)$} \\
1.03 & -2.09 & 0.91 & -0.21 & -0.18 & -0.24 & 0.14 & 0.23 & 0.69 & 0.51 & 0.96 & 0.81 \\
$(0.16)$ & $(0.42)$ & $(0.07)$ & $(0.06)$ & $(0.05)$ & $(0.09)$ & $(0.07)$ & $(0.08)$ & $(0.13)$ & $(0.05)$ & $(0.02)$ & $(0.09)$ \\
& & & & \multicolumn{8}{c}{$\operatorname{BBD}(2,4,1)$} \\
& & & & & & & & & \\
1.00 & -1.96 & 0.91 & -0.21 & -0.21 & -0.21 & 0.15 & 0.23 & 0.70 & 0.52 & 0.96 & 0.81 \\
$(0.15)$ & $(0.33)$ & $(0.07)$ & $(0.04)$ & & & $(0.07)$ & $(0.07)$ & $(0.13)$ & $(0.05)$ & $(0.02)$ & $(0.09)$ \\
\hline \hline
\end{tabular}

Standard errors in parentheses. Constrained coefficients in italic. $\phi_{i}$ 's are the autoregressive coefficients in eq. (1). 
given by $1 /\left(1-p_{11}\right)$, is 5 quarters while the average length of an expansion is six years and a quarter. This results are very similar to those found by Morley and Piger [2009]: their $p_{11}$ and $p_{00}$ estimates are respectively 0.79 and 0.94 for a sample ending in 2006Q4. Finally, the two shift parameters, $\delta_{\gamma}$ and $\delta_{\sigma}$, are significantly different from one: these mean and variance breaks are clearly supported by our results. The value of 0.7 for $\delta_{\gamma}$ implies a decrease in $\gamma_{0}$, the mean growth rate in the expansion regime, by $70 \%$ after 1973Q1. The decrease in the variance is even stronger since $\delta_{\sigma}$ estimate is around 0.5: the variance after 1984Q2 is a fourth of its value before $\left(\sigma_{t>1984 Q 2}^{2}=\sigma^{2} \times \delta_{\sigma}^{2}\right)$. A more detailed evaluation of the impact of the structural breaks on the mean and standard deviation parameters is reported in Table 10 in the Appendix. The smoothed probability of being in a contractionary regime reported in Figure 4 closely matches the NBER recession dates represented by the dotted line. For eight recessions out of eleven, the smoothed probability reaches more than $50 \%$ immediately or one quarter after the peak date. By contrast, for the 1970, 1973 and 2001 recessions, this probability increases but remains below $30 \%$.

The United Kingdom Since the structural break dates are not as much documented for the UK as they are for the US, the methodology described in Sensier and van Dijk [2004] is used to test for structural change in conditional mean and/or volatility. As a result, a mean break is detected in 1980Q1 at the 1.3\% level and a variance break, conditional on the mean break, in 1980Q2 at a level lesser than 1\%. Since these are two consecutive dates, corresponding to the election of Margaret Thatcher and the restrictive monetary policy she initiated then, both the conditional variance and the difference in growth rates across regime are allowed to change at the same date ${ }^{9}$, with the change in conditional variance assumed to be proportional to the squared change in the difference in growth rates.

\footnotetext{
${ }^{9}$ We have retained 1980Q2 but the results remain the same with 1980Q1. We also allowed for an additional break in mean in 1980Q1 but the estimated coefficient of this break was not significantly different from one.
} 


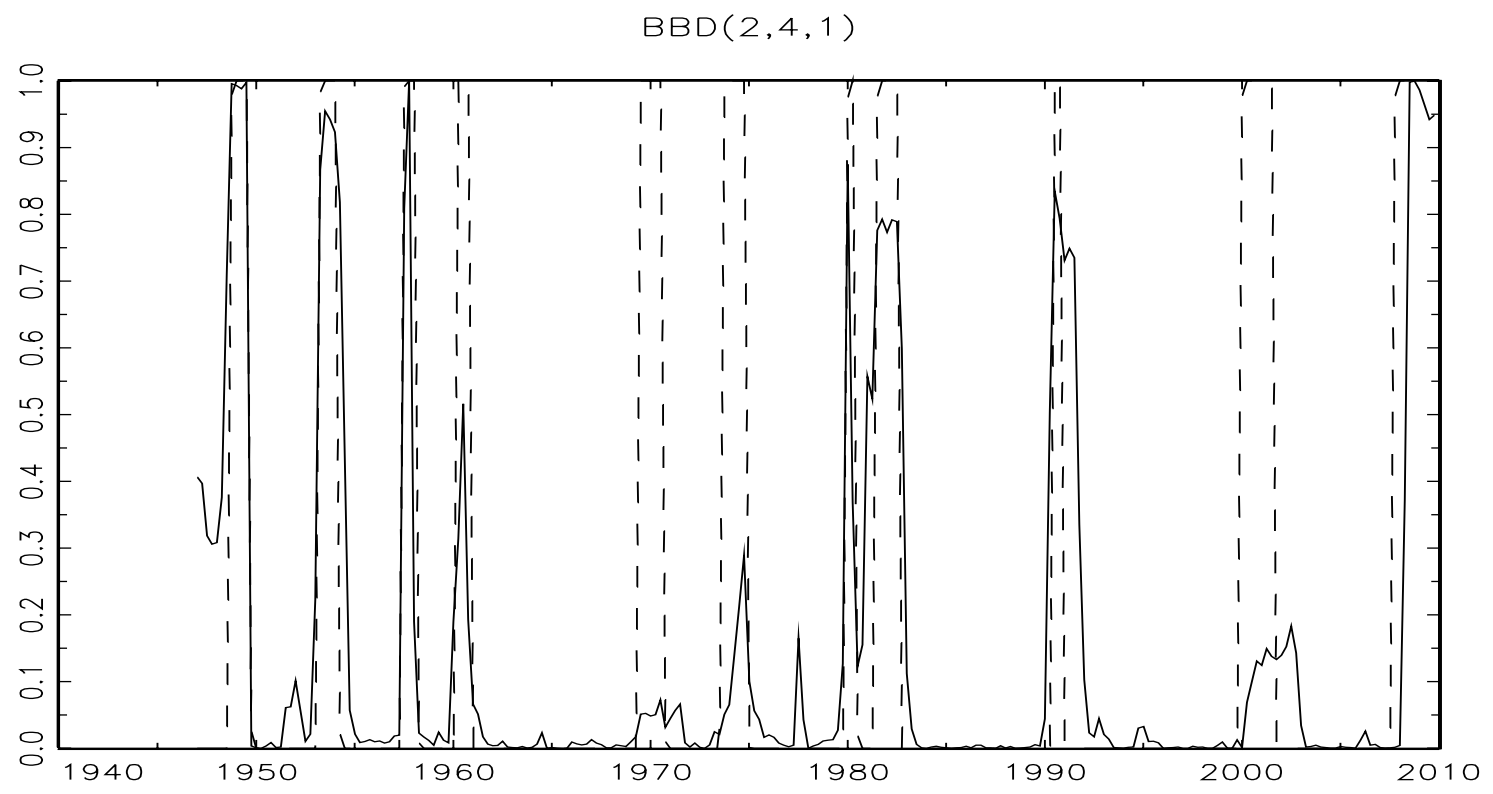

Figure 4: Smoothed probability of recession state for the US

According to the LM test of no serial correlation, the lag order for the BB models was set to zero: The p-values of the $\operatorname{LM}(4)$ and $\operatorname{LM}(8)$ tests are respectively $44 \%$ and $31 \%$ for our preferred BBF model. Then, for this lag order, the $\operatorname{BBF}(0,5,0)$ was found to maximize the log-likelihood: the bounce-back effect is longer than in the US case, but it is not delayed here. The AIC of linear autoregressive models and nonlinear BB models are reported in Table 5. As in the US case, all the regime-switching models clearly outperform the linear autoregressive ones. Then, among the nonlinear models, the BBF is preferred to BBU, BBV, BBD and Hamilton's models. The LR test statistics for the $\mathrm{BBU}, \mathrm{BBV}$ and BBD models against the BBF alternative always exceed the $5 \%$ critical value. These models' estimates of the bounce-back parameter $\lambda$ is basically zero so that they mimic Hamilton's model. Hence, this UK case emphasizes another advantage of the BBF approach: the BBF model allows for more general recovery shapes than the $\mathrm{BBU}, \mathrm{BBV}$ and $\mathrm{BBD}$ models. As can be seen from the $\operatorname{BBF}(0,5,0)$ parameters estimates reported in Table 6, only $\lambda_{1}$ is different from zero. Hence, we also report the results 
Table 5: Comparison of UK models

\begin{tabular}{cccccc}
\hline \hline Model & Log-L & $n_{p}$ & AIC & LR stat & p-val \\
\hline \multicolumn{5}{c}{ Linear } \\
$\operatorname{AR}(1)$ & -283.38 & 4 & -287.38 \\
$\operatorname{AR}(2)$ & -278.21 & 5 & -283.21 & & \\
$\operatorname{AR}(3)$ & -275.28 & 6 & -281.28 & & \\
$\operatorname{AR}(4)$ & -275.24 & 7 & -282.24 \\
$\operatorname{AR}(8)$ & -270.67 & 11 & -281.67 \\
$\operatorname{c}$ Bounceback \\
$\operatorname{BBF}(0,5,0)$ & -262.84 & 9 & $-\mathbf{2 7 1 . 8 4}$ & & \\
$\operatorname{BBU}(0,5,0)$ & -267.18 & 7 & -274.18 & 8.68 & 0.01 \\
$\operatorname{BBV}(0,5,0)$ & -267.18 & 7 & -274.18 & 8.68 & 0.01 \\
$\operatorname{BBD}(0,5,0)$ & -267.18 & 7 & -274.18 & 8.68 & 0.01 \\
$\operatorname{T}$ Hamilton & & \\
$\operatorname{H-AR}(0)$ & -267.18 & 6 & -273.18 & 8.68 & 0.03 \\
\hline \hline
\end{tabular}

Log-L denotes the log-likelihood.

$n_{p}$ is the number of parameters.

of the estimation of a constrained version of this BBF model were $\lambda_{2}$ and $\lambda_{3}$ are set to zero. The log-likelihood remains the same in the constrained BBF model, i.e. -262.84, and the AIC becomes -269.82 since the number of parameters is only 7. According to $p_{11}$ estimate, the average length of a recession would be eight quarters in the UK. By contrast, expansions would last fifty quarters, or 12.5 years in this country. The mean and variance shift in 1980Q2 is also significantly different from one: the $\gamma_{1}$ parameter is almost divided by three after this date, while the standard deviation decreases to 0.47. This is an even greater moderation than in the US. Further details are reported in Table 10, see the Appendix. Finally, a strong correspondence between the smoothed probability of being in the recession regime and the recession dates (dotted line) can be seen from Figure 5. The last two recessions in 1990 and 2008 are closely accounted for by the BBF model: the smoothed probability exceeds $50 \%$ immediately after the business cycle peak date. The first oil shock recession is also detected, in that the smoothed 
Table 6: UK Bounce-back models estimates

\begin{tabular}{ccccccccc}
\hline \hline$\gamma_{0}$ & $\gamma_{1}$ & $\sigma$ & $\lambda_{1}$ & $\lambda_{2}$ & $\lambda_{3}$ & $\delta_{\gamma, \sigma}$ & $p_{00}$ & $p_{11}$ \\
\hline \multicolumn{7}{c}{$\operatorname{BBF}(0,5,0)$} \\
0.74 & -2.12 & 1.26 & -0.14 & 0.00 & 0.00 & 0.37 & 0.98 & 0.88 \\
$(0.05)$ & $(0.24)$ & $(0.03)$ & $(0.07)$ & $(0.00)$ & $(0.00)$ & $(0.04)$ & $(0.01)$ & $(0.08)$ \\
& \multicolumn{7}{c}{ Constrained BBF $(0,5,0)$} \\
0.74 & -2.12 & 1.26 & -0.14 & 0.00 & 0.00 & 0.37 & 0.98 & 0.88 \\
$(0.05)$ & $(0.24)$ & $(0.03)$ & $(0.07)$ & $(0.00)$ & $(0.00)$ & $(0.04)$ & $(0.01)$ & $(0.08)$ \\
\hline \hline
\end{tabular}

Standard errors in parentheses. Constrained coefficients in italic.

probability increases to almost $30 \%$ just after the peak date, even though it hardly exceeds $30 \%$ over that recession period. Regarding the second oil shock recession, the model clearly detects it two quarters after its beginning and hence is a little bit late.

France For French data, the approach used by Sensier and van Dijk [2004] reveals two breaks: a mean break in 1974Q1 and a variance break in 1968Q4 are hence introduced in the bounce-back model's estimation. The smallest lag length of nonlinear models which succeeds in eliminating residuals autocorrelation is two: For the preferred BBD model below, the $\operatorname{LM}(4)$ and $\operatorname{LM}(8)$ p-values are $71 \%$ and $33 \%$ respectively. Regarding the bounce-back models, the values $m=4$ and $\ell=0$ are the ones which maximize the likelihood. The improvement of the Akaike criterion by the nonlinear models is not as large as it is for US and UK data. Nevertheless, the $\operatorname{BBF}(2,4,0)$ AIC dominates the one of the best linear model. Then, the $\operatorname{BBV}(2,4,0)$ model is clearly rejected at the $5 \%$ level against the corresponding BBF model according to the LR test: this probably stems from the fact that the bounce-back parameter is not significantly different from zero in this model, with an estimate equal to -0.04 and a standard error reaching 0.05. By contrast, the constraints imposed by the BBU and BBD are not rejected. Amongst these two candidates, the BBD exhibits a slight improvement compared to the BBU in terms of likelihood. BBD model's estimates are reported in Table 8. The two shift parameters are significantly different from one, which confirms the role of those structural breaks. 
Constrained $\operatorname{BBF}(0,5,0)$

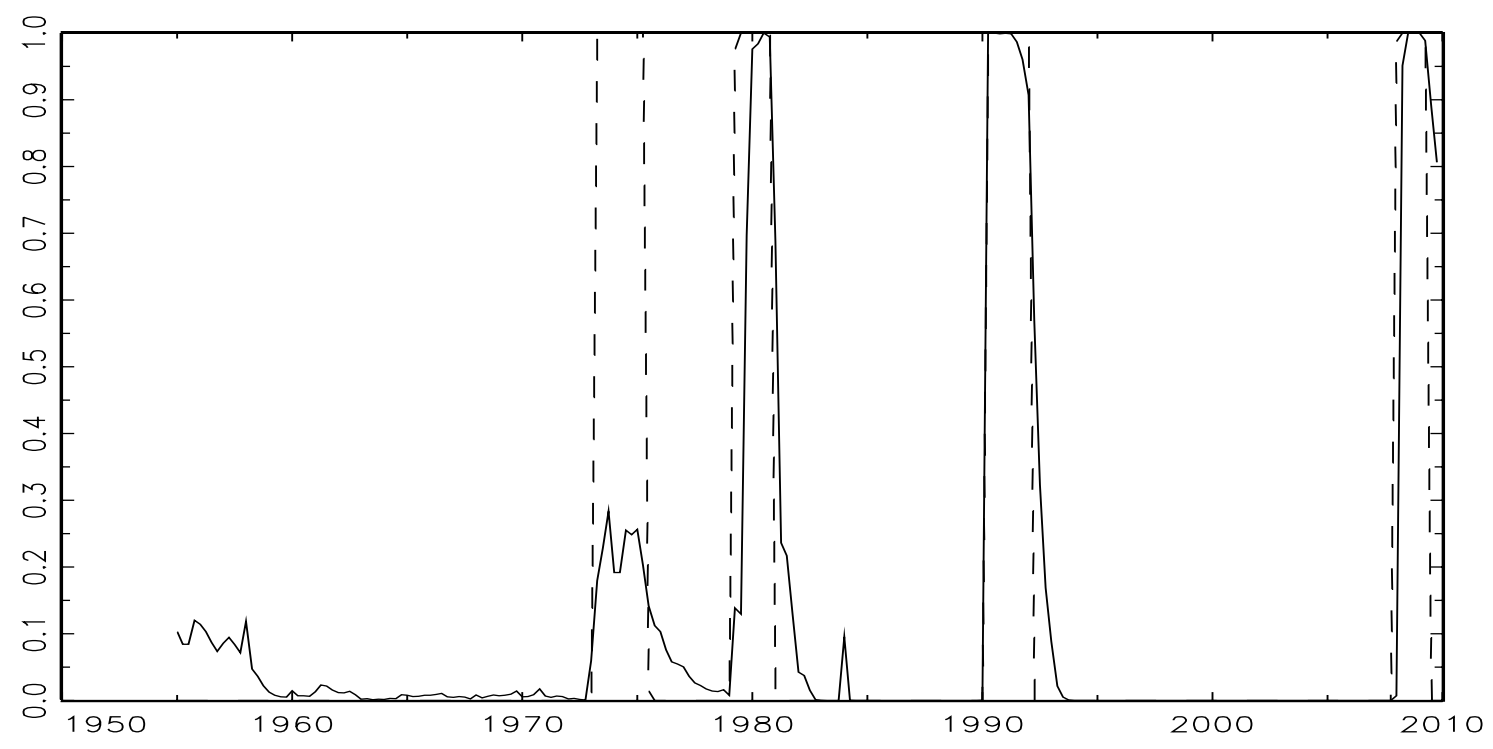

Figure 5: Smoothed probability of recession state for the UK

Table 7: Comparison of French models

\begin{tabular}{cccccc}
\hline \hline Model & Log-L & $n_{p}$ & AIC & LR stat & p-val \\
\hline \multicolumn{5}{c}{ Linear } \\
$\mathrm{AR}(1)$ & -218.03 & 5 & -223.03 & & \\
$\mathrm{AR}(2)$ & -211.17 & 6 & -217.17 & & \\
$\mathrm{AR}(3)$ & -210.59 & 7 & -217.59 & & \\
$\mathrm{AR}(4)$ & -205.67 & 7 & -213.67 & & \\
$\mathrm{AR}(8)$ & -201.87 & 11 & -213.87 \\
$\mathrm{c}$ Bounceback \\
$\operatorname{BBF}(2,4,0)$ & -200.24 & 12 & $\mathbf{- 2 1 2 . 2 4}$ & & \\
$\operatorname{BBU}(2,4,0)$ & -202.97 & 10 & -212.97 & 5.46 & 0.07 \\
$\operatorname{BBV}(2,4,0)$ & -205.64 & 10 & -215.64 & 10.80 & 0.00 \\
$\operatorname{BBD}(2,4,0)$ & -202.51 & 10 & -212.51 & 4.54 & 0.10 \\
$\mathrm{c}$ & Hamilton & & \\
$\mathrm{H}-\mathrm{AR}(2)$ & -205.73 & 9 & -214.73 & 10.98 & 0.01 \\
\hline \hline
\end{tabular}

Log-L denotes the log-likelihood.

$n_{p}$ is the number of parameters. 
Table 8: French bounce-back models estimates

\begin{tabular}{|c|c|c|c|c|c|c|c|c|c|c|c|}
\hline$\gamma_{0}$ & $\gamma_{1}$ & $\sigma^{2}$ & $\lambda_{1}$ & $\lambda_{2}$ & $\lambda_{3}$ & $\phi_{1}$ & $\phi_{2}$ & $\delta_{\gamma}$ & $\delta_{\gamma, \sigma}$ & $p_{00}$ & $p_{11}$ \\
\hline \multicolumn{12}{|c|}{$\operatorname{BBF}(2,4,0)$} \\
\hline $\begin{array}{c}1.33 \\
(0.24)\end{array}$ & $\begin{array}{c}-4.26 \\
(0.66)\end{array}$ & $\begin{array}{c}0.85 \\
(0.07)\end{array}$ & $\begin{array}{l}-0.28 \\
(0.03)\end{array}$ & $\begin{array}{l}-0.04 \\
(0.04)\end{array}$ & $\begin{array}{l}-0.04 \\
(0.05)\end{array}$ & $\begin{array}{c}0.23 \\
(0.06)\end{array}$ & $\begin{array}{c}0.36 \\
(0.06)\end{array}$ & $\begin{array}{c}0.48 \\
(0.11)\end{array}$ & $\begin{array}{c}0.47 \\
(0.05)\end{array}$ & $\begin{array}{c}0.99 \\
(0.01)\end{array}$ & $\begin{array}{c}0.94 \\
(0.05)\end{array}$ \\
\hline \multicolumn{12}{|c|}{$\operatorname{BBD}(2,4,0)$} \\
\hline $\begin{array}{c}1.32 \\
(0.25)\end{array}$ & $\begin{array}{c}-3.74 \\
(0.58)\end{array}$ & $\begin{array}{c}0.86 \\
(0.07)\end{array}$ & $\begin{array}{l}-0.17 \\
(0.03)\end{array}$ & -0.17 & -0.17 & $\begin{array}{c}0.27 \\
(0.06)\end{array}$ & $\begin{array}{c}0.34 \\
(0.06)\end{array}$ & $\begin{array}{c}0.47 \\
(0.11)\end{array}$ & $\begin{array}{c}0.48 \\
(0.05)\end{array}$ & $\begin{array}{c}0.99 \\
(0.01)\end{array}$ & $\begin{array}{c}0.88 \\
(0.10)\end{array}$ \\
\hline
\end{tabular}

Standard errors in parentheses. Constrained coefficients in italic.

$\phi_{i}$ 's are the autoregressive coefficients in eq. (1).

As can be seen from Table 10 in the Appendix, the standard deviation drops from 0.86 before 1968Q4 to 0.41 after this date, whereas the gap between expansion and recession regimes mean growth rates decreases from 3.74 to 1.79 from there on. Finally, the bounce-back parameter's estimate is -0.17 , which is slightly lesser in absolute value than the one found from the US data (-0.21). According to the BBD parameters estimates, a recession lasts around eight quarters on average, whereas an expansion would last about 25 years. Beside the fact that no recession occurred before the first oil shock, this striking result might stem from the fact that the model captures major recessions only, as can be seen from Figure 6. Actually, only half the recessions - the ones beginning in 1973 and 2008 - are well detected by the smoothed probabilities. In that respect, the bounce-back model seems less successful here than in the US and UK cases.

\section{Implications of estimated bounce-back models}

\subsection{Which kind of recovery shape?}

Using the BB models parameters estimates reported in the previous section, we obtain the typical shapes of recoveries specific to each country. They are plotted in Figure 7. According to our estimates, France experiences the deepest drop at the beginning of a 


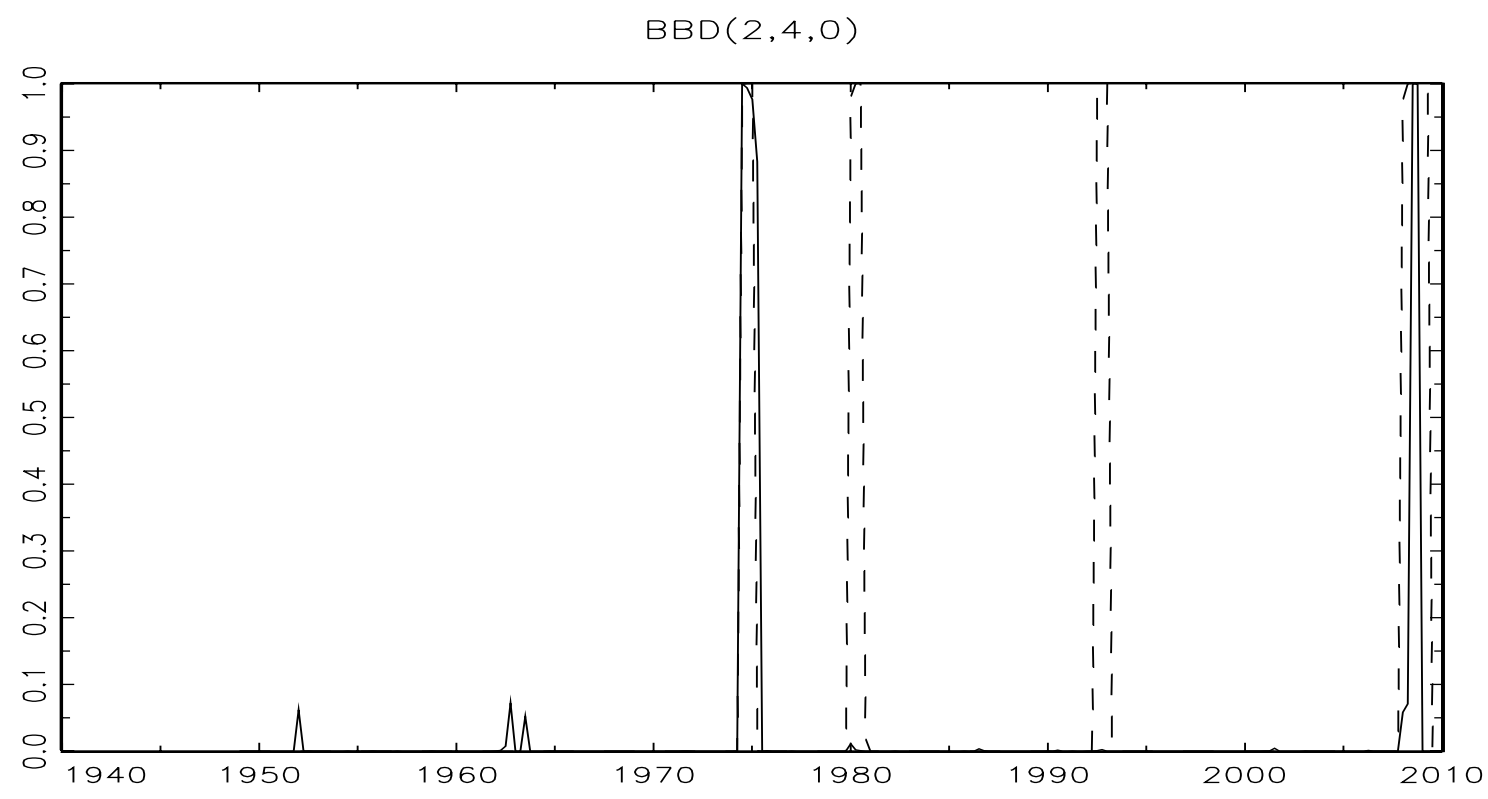

Figure 6: Smoothed probability of recession state for France

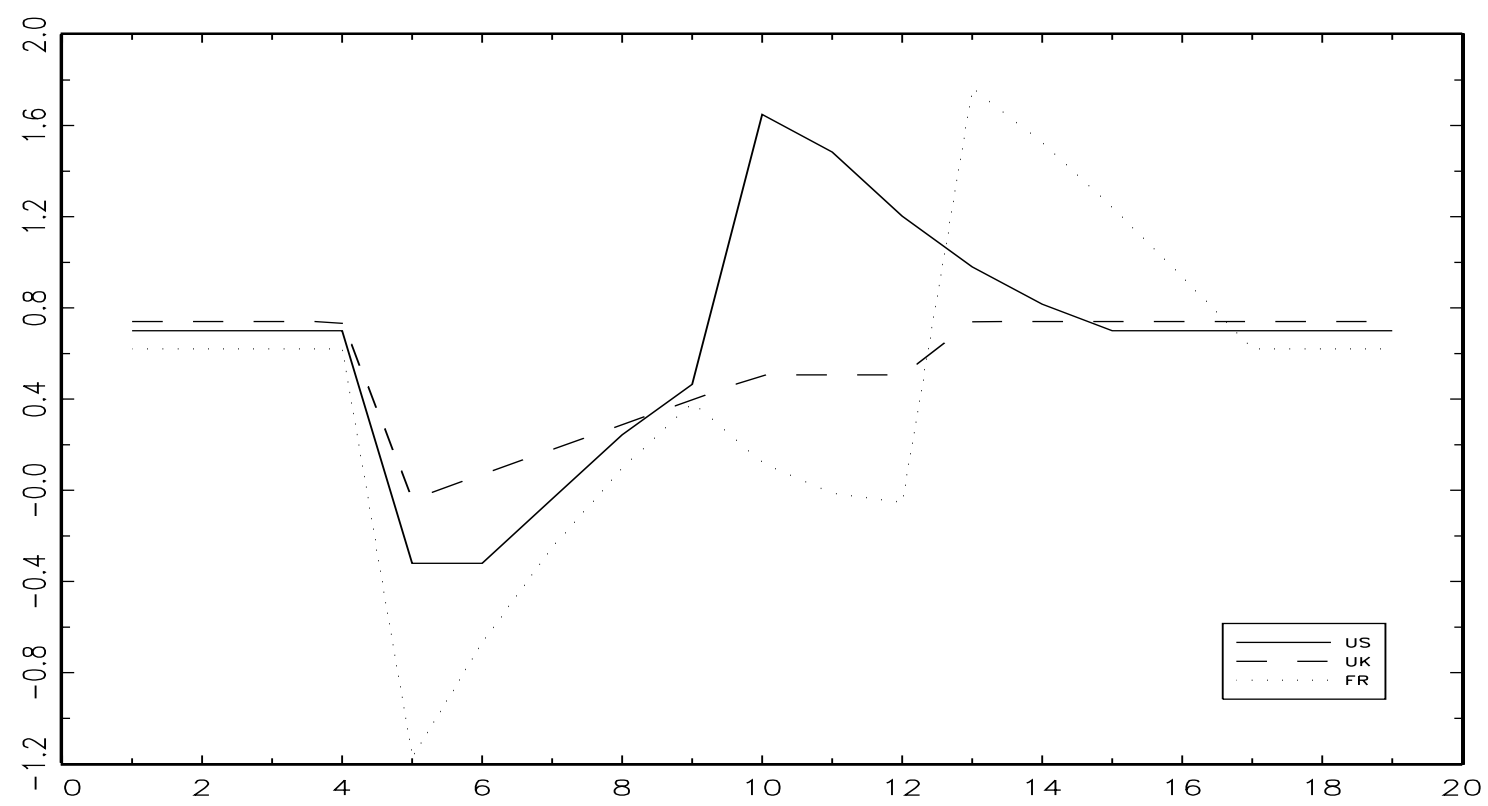

Figure 7: Estimated bounce-back effects 
recession, and then recovers for the next five quarters. The ' $\mathrm{W}$ '-like recession observed on this graph comes from the fact that $m=4$. This indeed implies that the first deep drop into recession vanishes from the bounce-back term $\left(\lambda \sum_{j=1}^{m}\left(\gamma_{1}+\Delta y_{t-j}\right) S_{t-j}\right)$ after five quarters, and then this last term becomes slightly smaller than the mean growth rate in recession, which explains the second drop. When finally $S_{t}$ goes back to zero after 8 quarters, the bounce-back term adds up to the mean growth rate in expansion, which translates into an overshooting effect. The French case illustrates the flexibility of the BBF model, in that it is also able to mimic some kind of W-type recession. The shape obtained for the UK stems directly from the estimated $m$ parameter which is 5 in this case while the average length of recession is 8 quarters. Hence, the bounce-back activates immediately after the first drop, then reaches its maximum value on the fifth quarter and stays at this level until $S_{t}$ goes back to zero. From there on, the mean growth rate in expansion regime dominates the dynamics. Finally, the bounce-back function obtained in the US is quite similar to the one corresponding to the $\operatorname{BBF}(0,4,1)$ that is plotted in Figure 3.

\subsection{Permanent impact of a recession}

Hamilton [1989] proposes to evaluate the permanent effects of recessions from the expected difference in the long-run level of output given that the economy is currently in the recession regime versus in expansion regime, which may be written as:

$$
\lim _{j \rightarrow \infty}\left\{E\left[y_{t+j} \mid S_{t}=1, \Omega_{t-1}\right]-E\left[y_{t+j} \mid S_{t}=0, \Omega_{t-1}\right]\right\}
$$

where $\Omega_{t-1}=\left\{S_{t-1}=0, S_{t-2}=0, \ldots ; y_{t-1}, y_{t-2}, \ldots\right\}$. Unfortunately, when bounceback terms depend on past growth rates, as in the BBF and BBD models, this limit as no trivial closed-form solution. Nevertheless, from Figure 7, it appears that the area defined by the difference between the BB function and the horizontal line set to $\gamma_{0}$, i.e. the growth rate associated to the expansion regime, provides a natural measure of the accumulated or permanent impact of a recession on the level of output. This measure is very close to the one suggested by Hamilton [1989] except for one aspect: In Hamilton's 
measure, starting from the expansion regime growth rate and after the time $t$ recession is over, the expected long-run output growth rate will not tend towards the expansion regime growth rate $\gamma_{0}$. Instead, the model's long-run expected growth rate is a weighted average of the expansion and recession regimes growth rates. In Figure 7, it would lie somewhere between the first value and the minimum value of the $\mathrm{BB}$ curves. As a result, the magnitude of Hamilton's measure of permanent loss should be slightly smaller than ours. However, we believe that an important intrinsic property of this two-regime MS class of models is to allow for the growth rate to go back to its expansion regime value after the end of the recession, and hence deliberately include this feature in our permanent impact evaluation. To this end, we compute numerically the limit given in equation (12) conditionally to the assumption that once the recession initiated at time $t$ in the first term is over, i.e. at time $t$ plus the estimated average recession duration, both expectation terms involved in this limit are governed by the same path for the state variable. The resulting values are reported in the first line of Table 9, and point to a permanent negative impact of recessions in all the countries considered. In the US, our

Table 9: Permanent impact evaluation

\begin{tabular}{cccc}
\hline \hline$\lambda$ & US & UK & FR \\
\hline$\lambda=\hat{\lambda}$ & $-1.02 \%$ & $-3.58 \%$ & $-3.71 \%$ \\
$\lambda=0$ & $-4.43 \%$ & $-5.57 \%$ & $-13.77 \%$ \\
\hline \hline
\end{tabular}

results suggest that a recession causes a $1.02 \%$ permanent drop in the level of GDP. This result is well in line with the 0.41 drop found by Kim et al. [2005] from a BBU model and Hamilton's measure. Without any bounce-back effect, i.e. with $\lambda=0$, the permanent drop would reach $4.43 \%$, as can be seen in the second line of Table 9 . In the UK and France, the permanent drops following a recession are respectively $3.58 \%$ and $3.71 \%$. It is worth noting that in the French case, the gain from the bounce-back effect is particularly large since without it, the permanent drop in the GDP level would reach $-13.77 \%$. This large discrepancy comes from the size of $\gamma_{1}$ which is much larger in absolute value than 
the ones obtained for the two other countries. Moreover, this French result is very much in line with the permanent loss in the potential output estimated by the IMF in its 2010 report $^{10}$ at $3.5 \%$. Regarding the UK, Kim et al. [2005] evaluate this permanent loss at $5.34 \%$ for data from 1973 to 2006, while based on a simple production function estimate, the IMF 2009 staff report ${ }^{11}$ suggests that "the cumulative loss of potential output over 2008-2010 could be as large as 4 to 5 percentage points". The Kim et al. [2005] estimate basically relies on a Hamilton's model without bounce-back effect, which is the model we would also have selected if the BBF model had not been considered. Remark that by setting $\lambda$ to zero, we obtain a very similar permanent impact: $-5.57 \%$. Finally, it is also worth noticing that the IMF estimate mentioned above considers the last recession only, and hence may over-estimate the average permanent impact of a recession in the UK.

\section{Concluding remarks}

In this paper, we propose an original bounce-back model embedding existing ones while allowing for new shapes of bounce-back functions. This BBF model allows for formal statistical testing of standard bounce-back functions as the BBU, BBV or BBD ones. Our application to three countries GDPs emphasizes the flexibility and relevance of the proposed framework. For instance, the preferred model for UK data is a constrained version for the BBF model which does not belong to the standard ones. Moreover, extending the analysis to other countries than the US also points to the country-specific shapes of recoveries. As seen above, the framework also allows for 'W'-like recession preceding the recovery episode. Finally, this class of models suggests less pessimistic conclusions than the original Hamilton's model in terms of the permanent effects of a recession on the level of GDP: even though the permanent impacts of recessions are still

\footnotetext{
${ }^{10}$ See the IMF country report No. 10/240, France: 2010 Article IV Consultation - Staff report, July 2010, p. 13.

${ }^{11}$ See the IMF country report No. 09/212, The United-Kingdom: 2009 Article IV Consultation Staff report, July 2009, p. 25.
} 
negative, their magnitudes are quite reduced thanks to the bounce-back effect. From an economic theory perspective, these results question the importance of the cleansing effects of recessions put forward by endogenous growth models belonging to the Schumpeterian tradition. 


\section{References}

Aghion, P. and G. Saint Paul, Virtues of bad times: intercation between productivity growth and economic fluctuations, Macroeconomic Dynamics, 1998, 2 (3), 322-344.

— , P. Askenazy, N. Berman, G. Cette, and L. Eymard, Credit Constraints and the Cyclicality of RD Investment: Evidence from France, Working Paper 198, Banque de France, Paris 2008.

Bai, J., R.L. Lumsdaine, and J.H. Stock, Testing For and Dating Common Breaks in Multivariate Time Series, Review of Economic Studies, 1998, 65, 395-432.

Beaudry, P. and G. Koop, Do Recessions Permanently Change Output, Journal of Monetary Economics, 1993, 31, 149-163.

Bec, F., A. Rahbek, and N. Shephard, The ACR Model: A Multivariate Dynamic Mixture Autoregression, Oxford Bulletin of Economics and Statistics, 2008, 70, $583-619$.

Birchenhall, C., D. Osborn, and M. Sensier, Predicting UK Business Cycle Regimes, Scottish Journal of Political Economy, 2001, 48 (2), 179-195.

Bry, G. and C. Boschan, Cyclical Analysis of Time Series: Selected Procedures and Computer Programs, New York and London: Columbia University Press, 1971.

Burns, A. and W. Mitchell, Measuring Business Cycles, New York: National Bureau of Economic Research, 1947.

Caballero, R. and M. Hammour, The Cleansing Effect of Recessions, American Economic Review, 1994, 84 (1), 350-368.

Carrasco, M., L. Hu, and W. Ploberger, Optimal Test for Markov Switching Parameters, Manuscript, University of Montreal, Canada 2009. 
Cerra, V. and S. Saxena, Growth dynamics: The myth of economic recovery, Wprking paper 05/147, IMF 2005.

Clements, M.P. and H.-M. Krolzig, A comparison of the forecast performance of Markovswitching and threshold autoregressive models of US GNP, Econometrics Journal, 1998, 1, C47-C75.

_ _ and _ _ Business Cycle Asymmetries: Characterization and Testing Based on Markov-Switching Autoregressions, Journal of Business and Economic Statistics, 2003, 21, 196-211.

Davidson, R. and J. MacKinnon, Econometric Theory and Methods, Oxford University Press, 2004. New-York.

Friedman, M., The "plucking model" of business fluctuations revisited, Economic Inquiry, 1993, 31 (2), 171-177.

Furceri, D. and A. Mourougane, The effect of financial crises on potential output, Working paper 699, OECD Economic Department 2009.

Hamilton, J., A new approach to the economic analysis of nonstationary time series and the business cycle, Econometrica, 1989, 57, 357-384.

Harding, D. and A. Pagan, Dissecting the Cycle: a Methodological Investigation, Journal of Monetary Economics, 2002, 49, 365-381.

Kim, C.-J. and C. Nelson, Has The U.S. Economy Become More Stable? A Bayesian Approach Based On A Markov-Switching Model Of The Business Cycle, The Review of Economics and Statistics, 1999, 81, 608-616.

, J. Morley, and J. Piger, Nonlinearity and the permanent effects of recessions, Journal of Applied Econometrics, 2005, 20, 291-309. 
Kim, S., N. Shephard, and S. Chib, Stochastic Volatility: likelihood inference and comparison with ARCH models, The Review of Economics Studies, 1998, 65, 361393.

Luukkonen, R. and T. Terasvirta, Testing Linearity of Economic Time Series Against Cyclical Asymmetry, Annales d'Économie et de Statistique, 1991, 20/21, 125-142.

Martin, P. and C. Rogers, Stabilization Policy, Learning-by-Doing, and Economic Growth, Oxford Economic Papers, 1997, 49 (2), 152-166.

McConnell, M. and G. Perez-Quiros, Output fluctuations in the US: what has changed since the early 1980s?, American Economic Review, 2000, 90, 14641476.

Morley, J. and J. Piger, The asymmetric business cycle, Manuscript February, Washington University in St. Louis 2009.

__ _ _ and P.-L. Tien, Reproducing business cycle features: How important is nonlinearity versus multivariate information?, Manuscript May, Washington University in St. Louis 2009.

Neftci, S.N., Are Economic Time Series Asymmetric Over the Business Cycle?, Journal of Political Economy, 1984, 92, 307-328.

Sensier, M. and D. van Dijk, Testing for volatility changes in U.S. macroeconomic time series, The Review of Economics and Statistics, 2004, 86 (3), 833-839.

Sichel, E., Inventories and the Three Phases of the Business Cycles, Journal of Business and Economic Statistics, 1994, 12 (3), 269-277.

Stadler, G., Business Cycle Models with Endogenous Technology, American Economic Review, 1990, 80, 763-778.

Stiglitz, J., Endogenous Growth and Cycles, Working Paper 4286, NBER 1993. 


\section{Appendix}

Table 10: Structural breaks impact on growth rates mean and standard deviation

\begin{tabular}{lccc}
\hline \hline & US & UK & France \\
\hline Model & $\operatorname{BBD}(2,4,1)$ & $\operatorname{BBF}(0,5,0)$ & $\operatorname{BBD}(2,4,0)$ \\
Mean break, $t_{0}$ & $1973 \mathrm{Q} 1$ & none & $1974 \mathrm{Q} 1$ \\
$\delta_{\gamma}$ & 0.70 & - & 0.47 \\
Variance break, $t_{1}$ & $1984 \mathrm{Q} 2$ & $1980 \mathrm{Q} 2$ & $1968 \mathrm{Q} 4$ \\
$\delta_{\gamma, \sigma}$ & 0.52 & 0.37 & 0.48 \\
$\gamma_{0, t \leq t_{0}}$ & 1.00 & 0.74 & 1.32 \\
$\gamma_{0, t>t_{0}}$ & 0.70 & 0.74 & 0.62 \\
$\gamma_{1, t \leq t_{1}}$ & -1.96 & -2.12 & -3.74 \\
$\gamma_{1, t>t_{1}}$ & -1.02 & -0.78 & -1.79 \\
$\sigma_{t \leq t_{1}}$ & 0.91 & 1.26 & 0.86 \\
$\sigma_{t>t_{1}}$ & 0.47 & 0.47 & 0.41 \\
\hline \hline
\end{tabular}

